\title{
INTERPRETATION IN ONTARIO PROVINCIAL PARKS
}

\author{
BY A. F. HELMSLEY ${ }^{1}$
}

The term "Park Interpretation" is comparatively new in Canada and probably requires an explanation. It may be defined as the art of imparting, to park visitors, accurate information concerning the park environment which, in totality, consists of geology, topography, climate, soil, flora, fauna and human history. The term, "interpretation", although academically correct, is not in general use. For general use, the term "Naturalist Program" is perhaps more meaningful to park visitors.

The methods usually employed in park interpretation consist of museums, exhibit centres, self-guiding trails, conducted trips, hikes or tours, illustrated talks or demonstrations, and park publications.

We have noted that park interpretation is an innovation in Canada. For some 40 years, however, the United States National Parks Service has carried on interpretive programs, and now many state park systems recognize the importance of this service. Several United States metropolitan areas, and comparatively recently, Metropolitan Toronto and Region Conservation Authority, have been operating interpretive services for many years. Recently, the United States Forest Service has established its Visitor Information Service to interpret forest management practices to a vacationing public.

In Canada, British Columbia entered the field a few years ago with growing success in its "nature houses" and the Canadian National Park Service has its Interpretive and Education Section, which has been establishing nature trails and a service of conducted trips and film showings in many National Parks. Alberta and Saskatchewan have undertaken, with some very fine presentations in provincial parks, self-guiding trails and exhibit centres.

Ontario began its provincial park interpretive service in 1944, when at the request of the Department of Lands and Forests, Dr. J. R. Dymond, then Director of the Royal Ontario Museum of Zoology, later Head of the Zoology Department of the University of Toronto and now retired, began a program of conducted hikes and illustrated talks in Algonquin Provincial Park. In the following year, Dr. Dymond received the benefit of an assistant and in 1946 a tent museum was established. Today, through the media of conducted trips, illustrated talks and self-guiding trails, complete programs of interpretation are presented in seven provincial parks. Of these, four have park museums. In addition, two other provincial parks have historical museums and four have exhibit centres. This year, in addition to two permanent staff in Head Office and two permanent staff in the field, 24 seasonal interpretive staff consisting of university students, teachers and senior high school students, were employed in provincial parks. Last year, more than a half million park visitors participated in these programs and visited museums. An unknown number visited exhibit centres.

${ }^{3}$ Supervisor of Park Interpretation, Parks Branch, Department of Lands and Forests. 
Originally referred to as nature programmes or nature education, the present term, park interpretation, was adopted when human history became involved and when an analysis of the objectives had been made. Why do we offer the park visitor interpretation? Essentially, we want to help the visitor to see the park's significant features. Then, having drawn his attention, we want to encourage his interest, his understanding and his appreciation. Through all this, the visitor's park experience becomes enriched and perhaps there may be gained the visitor's interest and cooperation in resource management. While nature education may accomplish all these, it may neglect the human history aspect, which can be equally inspiring. Nature education seems to possess a formal character requiring a course with regular attendance and a progression in subject material. Also, it may be presented in almost any outdoor situation. Park interpretation, however, includes natural and human history, is specific to a particular park, deals mainly with large, significant features and is designed for people, who are enjoying vacations and who probably do not remain for very long in the particular park.

Although we will see, in slides, glimpses of the various interpretive media in provincial parks, each of the methods is worthy of a few moments consideration.

Exhibits may be housed in a park museum, an exhibit centre or in an outdoor display case. The field of exhibits is too specialized to be treated here, but let it be noted that the exhibit is a medium for the presentation of information, ideas, concepts, and objects. It must attract the viewer's attention for a period of time sufficient for him to gain the message in an amount, and manner, conducive to awakening an interest in the subject. The exhibit should not provide all the available materials which soon become "storage on display". One projectile point in an archaeological exhibit is more effective than fifty similar points.

The subject of park museums would require a separate paper. Briefly, the museum serves as a focal point for the complete program and houses the collections upon which the interpretation is based. It is, however, only one interpretive tool. The museum reaches many park visitors, who do not avail themselves of the other interpretive activities. One function of a park museum and its exhibits, is to encourage a visitor to become more intimate with the park through the trails, conducted trips, and talks.

A very useful interpretive means is the exhibit centre, which may consist of a single exhibit case or several cases. It may be located at the actual site to be interpreted and through the use of maps, diagrams, photographs, sketches, objects and texts explains what the visitor is viewing at the time. Such centres are self-explanatory, require no special interpretive staff and very little supervision and maintenance.

All trails leading through natural areas are nature trails. Although they provide access to such areas, they do not offer interpretation unless the various aspects of the trail environment are indicated by labels or some guiding system. The labelled trail, and there are many ways of carrying out the actual labelling, is really a series of exhibits in their natural places. The exhibits consist, chiefly, of the trees, shrubs, and herbaceous plants, because they are easily labelled. To prevent such trails from becoming strictly 
botanical trails, however, every effort is made to label evidences of wildlife. In addition, labels describe the particular forest type, soil conditions, and other environmental aspects to give the hiker the broader aspects of the trail, as well as the detail. There are advantages in labelled trails, in that visitors may use them at their leisure and there is no scheduling of times and meeting places. Although the presence of a leader is not required, constant trail maintenance is necessary. In the past few years, self-guiding trails have undergone a change in labelling technique. Highly favoured, today, are the numbered stations and appropriate texts in a guide booklet. This has the advantage of "take away" value for the serious visitor, who would like a future reference. It also permits more space and opportunity for descriptive and explanatory text. Less maintenance is required on numbered stations and vandalism seems to be reduced.

The conducted trip is a most effective interpretive method. The leader is in direct, personal contact with park visitors and the subjects to be interpreted are right at hand. The interpreter is not limited to the confined space of a label or an exhibit and he may choose his material as it appears. His interpretation may be geared to the particular group, and visitors may ask questions. This situation is ideal. The trip provides visitors with an actual experience in the park environment which is being interpreted.

Illustrated talks hold an important place in park interpretation, in that they may be used to present certain park aspects, which are not available during the summer, or are not encountered on a trip. Talks also form a contact with visitors who are not free, or are not physically able to take advantage of the conducted trip. One distinct advantage of talks is that they may be presented to groups outside the park during any season. Finally, the talks may sometimes illustrate principles and concepts more easily and more effectively through diagrams and pictures on slides. The success of the illustrated talk depends upon the interpreter's selection of subject, his camera, his slides and his voice. Much is demanded of him. This is particularly important when we consider the turnover in seasonal staff and the possibilities of obtaining the services of such an ideal person. To overcome, in part, some of these difficulties we are now exploring the preparation of taped talks geared to slides for standard talks in certain parks. Although it loses something of the personal touch, we feel that it may gain more time for interpretive staff in other interpretive pursuits which cannot benefit from mechanical aids.

Publications, concerned with parks, may simply provide guidance and general visitor information or may be specialized to provide interpretation. At the present time, some provincial parks with interpretive services offer checklists of the flora and fauna recorded in the particular park. Specific subjects may be treated adequately in small booklets. Some may be brief publications describing historical periods or events, such as our booklet on Nancy Island. Others, such as the "Reptiles of Algonquin Park", deal with a small group of animals. Subjects, such as the birds or flowering plants of a particular park are beyond the scope of most park agencies. On the market, today, are so many good books that perhaps it is sufficient to provide only lists 
and simple publications for park visitors. Publications are important in that visitors may obtain them in preparation for a park visit and have them for future reference.

As a final point, in the consideration of methods, all forms of park interpretation are focussed on the park, which is being interpreted. There is no place for other subjects, such as general travelogues, and the like. The showing of certain films, unless related to the park, may be considered as education, but is not park interpretation. The entire program may possess entertainment qualities, and certainly recreational features. The prime objective, to gain visitor interest, understanding and appreciation, however, must be upheld.

It is difficult to measure the success of park interpretive programs. The public response, as indicated by the ever-increasing attendance figures, has been very great. For those interested in figures, the following attendance data are listed for the 1963 season:

$\begin{array}{lr}\text { Museum Registration } & 371,000 \\ \text { Nature Trail Registration } & 62,000 \\ \text { Conducted Trip Attendance } & 11,000 \\ \text { Talks Attendance } & 51,000\end{array}$

A measure of success is shown by the actual interest and questions of visitors and by the visitors, who return to a particular park each summer, and seldom miss a conducted trip and talk.

It must be pointed out that the success of park interpretive programs cannot, and should not, be measured in attendance numbers. The programs will never interest and attract every park visitor. This is fortunate, because such numbers could not be accommodated by the present interpretive facilities and staff which, even now, are being pushed to the limit and, in some cases, beyond. This situation has been reached in some United States National Parks, in which some interpretive services have had to be abandoned during the peak visitor season, because of the sheer weight of numbers. In Ontario, last summer, some conducted trips attracted an average attendance of 86 hikers per trip, under the leadership of one park naturalist. Startling attendances have reached the 200 mark on certain occasions. From all this, we may say that interpretation provides the visitor with the key to the park environment and indicates the points of greatest interest and inspiration. It enlarges the visitor's experience and presents the environment in recognizable and understandable terms. Most important is the presentation of man's relationship with his environment. Visitors are made aware of their place, not apart from the outdoor world, but as an integral part of it, both influencing it and being influenced by it. Through these interesting and enjoyable experiences, which are both educational and recreational, interpretation contributes to the inspirational value of the outdoors and fosters an understanding, an appreciation, and an intelligent use of our parklands. This does not mean that there is a hope of every park visitor becoming enrapt beyond words with a deep feeling for the world of nature.

Our interpretive staff is urged to provoke thought and to promote modern concepts of our environment. Visitors become aware of forests as dynamic 
communities. They learn of the natural successions due to natural fires and of natural destruction due to wind and flood. They learn that wildlife responds to these changes. Thought is given to the definition of the words "natural" and "wilderness". Discussions, in our large parks, include the economic aspects of forests and the pros and cons of logging, trapping, hunting and total protection. Our hope, therefore, is that the visitor will continue to enjoy his camping, picnicking, bathing, fishing, loafing and puttering and, at the same time, have an understanding and appreciation of the natural environment, which provides the place for these activities. If he becomes deeply interested, so much the better. 